\title{
Problems Existing in the Curriculum of Chinese Early Childhood Education Institutions and the Suggestions*
}

\author{
Wei Guo \\ Preschool Education College \\ Shaanxi Xueqian Normal University \\ Xi'an, China
}

\begin{abstract}
Curriculum is the core and soul of early childhood education institutions, and determines the quality and effectiveness and even the survival of early childhood education institutions. At present, there are many problems in the sources, theoretical basis, target positioning, content, implementation process, and evaluation system of curriculum of Chinese early childhood education institutions. Such problems seriously affect the quality and effectiveness of early childhood education institutions' education and restrict the development of early childhood education. Hence, they are needed to be optimized and improved from many aspects.
\end{abstract}

Keywords-infants; early childhood education institutions; curriculum setting; problems and suggestions

\section{INTRODUCTION}

Early childhood institutions emerged as the importance of early childhood education for infants aged 0-3 was widely recognized, people's understanding of early childhood education gradually deepened, and many families tried to use social forces to assist in the implementation of early childhood education. Since the establishment of China's first early childhood education institution in the late 1990s, early childhood education institution has had a 20-year history in China. Various types of early childhood education institutions have experienced a sharp increase in quantity, but their qualities were at different levels. In this research, literature method is used to analyze the status quo and existing problems of the early childhood education institutions collected all over China. At the same time, observation method, interview method, comparative method and other research methods are also used for making field investigation on more than ten famous and popular early childhood education institutions to reveal their curriculum characteristics, status quo, and problems, and provide relevant thought and suggestions.

*Funds: 1. 2018 Shaanxi Colleges and Universities Innovation and Entrepreneurship Education Course "Creation and Operation of early childhood education institutions" (Subject No. 151)

2. 2018 Shaanxi Xueqian Normal University's Teaching Reform Project "Application Research of Project-based Teaching Methodology in the Cultivation of Innovative and Entrepreneurship Teachers for Preschool Education Major" (Subject No. 18JG044Y)
Curriculum, as the core of education, is directly related to the quality and effectiveness of education, as well as the physical and mental development of students. The curriculum of early childhood education institutions is both the core of early childhood education and the soul of early childhood education institutions. It is related to the education quality and effectiveness of such institutions. It is the fundamental guarantee for them to settle down and seek long-term development. It is also the capital that early childhood education institutions use to attract parents and infants and determines the number of students and the source of funds which are relevant to the survival of such institutions.

\section{PRoblems EXISTING IN THE CURRICUlum OF CHINESE EARLY CHILDHOODEDUCATION INSTITUTIONS}

At present, the early childhood education institutions in China's market can be roughly divided into three categories: international chain institutions, domestic chain institutions and local institutions. Among those early childhood education institutions, there are many excellent institutions that have formed their own unique curriculum characteristics. However, it is true that the early childhood education market is a mixed bag, full of a number of institutions that only pursue economic benefits and do not value education quality. There are various problems:

\section{A. The Course Source Is Simply Grafted and Lacks Applicableness}

In order to enhance the influence on the market and cater to the demands of more parents, all the three categories of early childhood education institutions may highlight the characteristics of their respective curriculum. Basically, the courses of international institutions are sourced from their foreign headquarters, introduced into China by Chinese headquarters, and copied and used in their chain institutions all over the country. Most domestic chain institutions have their own curriculum development teams. They often use advanced foreign education theories to develop a relatively complete curriculum system based on the physical and mental development characteristics of infants and young children. Over many times of practice, they copy the 
curriculum system of foreign headquarters, measure domestic infants and children under the standard for measuring foreign infants and children, and provide guidance to domestic parents in the cultivation opinion for guiding foreign parents. In this way, it is inevitable to appear difference in culture and national conditions and difficult to ensure that the institution is in line with the condition and local characteristics of China. It is also difficult to guarantee the suitability of such courses in every province, city, and chain in promoting the courses developed by the domestic headquarters in the chain institutions. As the course is assembled by combining the strengths of many other institutions' courses, there must be a sense of incompatibility and rigidity in the connection between courses and the implementation of various courses.

\section{B. The Theoretical Foundation of the Course Exists in Name Only and Lacks Guidance}

When advertising for admissions, many early childhood education institutions may use some internationally renowned early childhood education theories as enrollment gimmicks to attract parents and claim that their theoretical foundations and curriculum setting concepts are supported by those theories. Among the more than ten early childhood education institutions surveyed, multiple intelligence theory, Carl Orff's music education theory, Montessori education theory, Reggio education theory, and brain science theory were all shown as the curriculum concepts of early childhood education institutions.

However, most of the institutions' expressions of those theories are superficial, without deep understanding and elaboration of them. At the same time, the applicability of those educational theories has yet to be verified. It is difficult to determine that each theory is surely suitable for infants and young children aged 0-3 years old, and for infants and young children aged 0-3 years and families in current China. There are also some early childhood education institutions exaggerating the novel educational theories. It is difficult to guarantee the suitability, let alone the role of providing guidance. Even if the suitability of the educational theories is guaranteed, it is even more difficult to grasp and measure whether those educational theories are actually implemented and applied in the real early childhood education implementation process and the extent of guidance the theories play in the application process.

\section{The Positioning of the Course Goals Is Ambiguous and Lacks Pertinence}

Some institutions' courses are only for infants and young children, and pay more attention to the development of their perception, motor skills, cognitive abilities and thinking, emotions and sociality. Even teachers only lead children to do activities, without participation of parents, and fail to provide effective guidance for parents. Parents do not know how to communicate and interact effectively with their babies to establish a good parent-child relationship; they do not know the reason for and suitability of their baby's certain behaviors as well as how to guide them to correct it; they do not know how to use available resources in daily life to provide a reasonable and appropriate education for their babies to promote their babies' healthy development and growth. Most of such institutions can clearly recognize that they bear the task of guiding parents, and even develop special curriculum content for this. However in the actual implementation, parents are rarely provided with corresponding guidance. After all, the goals and methods of parent-oriented course and child-oriented course are completely different. It is unrealistic to integrate the two courses organically and achieve significant results through a short-term parent-child course.

In this study, when analyzing the curriculum introduction and curriculum standards of various institutions, it was found that many of such institutions have not that clear orientation and description of their curriculum goals, and some of them only explain the staged goals for infant development, lacking goals in various fields; the goals in each field may be contained in the description of some institutions; but in general, the objectives of those curriculums are more an overall expression of the development results of infants and young children; few institutions' curriculum goals can involve the individual difference of each infants and young children and put forward different goals. In fact, for infants and young children aged 0-3, their growth and changes are constantly changing. Children whose ages are several months apart may have very different development status.

\section{The Course Content Emphasizes Teaching Other Than Cultivation and Lacks the Flavor of Life}

Many early childhood education institutions combine Montessori courses, Orff music education, sensory integration training courses and so on as the main structure of their own courses, involving infants and young children's movements, cognition, language, emotions, social communications and the like aspects. Those contents are linked by games and few involve the daily life of infants and young children. What's more, they arrange too much language activities such as stories and nursery rhymes while neglecting the development of infants and young children's hands-on ability. This way is away from the lives of infants and young children so that infants and young children cannot really experience the meaning and value of life [2]. The course rarely involves the eating and sleeping, living and washing of infants and young children and also lack guidance to parents in those aspects. Although teacher explains to parents in the implementation of the course, the explained content is more about the game or activity, and the intention of the game settings and the role of the game, etc. There is insufficient or even no guidance for parents in aspects of daily life care, nutrition feeding, and creation of a reasonable home cultivation environment. In this way, "the content integrating breeding and teaching as the most important growth path in early development of infants and also the content to be learned by parents the most is not involved in most parent-child courses". 


\section{E. Curriculum Implementation Is Constrained by Form and Lacks Creativity}

Seen from the specific activity plan written by the teachers, the implementation processes of the courses of early childhood education institutions are basically similar, including cognition, music, action, language, emotion, sociality and other aspects, and are completed by one by one games and activities with strict time and sequence requirements; the games often disconnect the link between games of different fields and are randomly combined, lacking intrinsic logic and connectivity so that the transition between games appear rigid and unsmooth; children and parents more often passively follow after the teacher to shift from one field of game to another; children are often enjoying in one field of game when the next game has been started. This way breaches infants and young children's psychological development characteristics such as learning transfer and attention transfer. [3] Teachers in early childhood education institutions are more likely to strictly follow the already-designed activity plan and implement the curriculum step by step, lacking attention to the immediate feelings of infants and parents, lacking the willingness to adjust the activity plan according to the actual situation, and lacking the ability to develop course resources and generate new courses based on the actual teaching process; the course implementation process lacks flexibility, integrity, themes, and creativity.

\section{F. The Course Evaluation System Is Incomplete and Lacks Scientificity}

The course evaluation contents of early childhood education institutions should include the course structure and plan, the course implementation process, and the implementation effect. The evaluation of the course implementation process is mainly to evaluate the fluency and education nature of the course implementation process, the reactions and performance of parents and infants in the course activities, the attitudes and behaviors of teachers, the interaction between teacher and parents and infants, teaching environment creation and other aspects. The evaluation of the implementation effect is mainly to evaluate the development of infants and young children after the course activities, the scientific parenting concepts, knowledge, and methods acquired by parents, and the produced effects within and beyond the expectation. [4]

At present, the course evaluation of early childhood education institutions mainly focuses on the course implementation process and the implementation effect, lacking evaluation on the course structure and plan. Moreover, the purpose of the early childhood education institution's evaluation of the course implementation process is to adjust the teaching methods and skills of teachers to achieve standardization and uniformity of the curriculum, rather than to timely adjust the curriculum setting and implementation upon finding any problem; the evaluation on the implementation effect mainly focuses on infants' development and neglects parents' benefits. With respect to the evaluation on infants' development, there is also a problem that the evaluation standards are not scientific enough. Many early childhood education institutions treat infants' natural development in physical and mental growth with the increase of age as the effect of the course implementation. There are also many teachers in early childhood education institutions that use their professional advantages to randomly draw conclusions about the development of infants and young children, to confuse and mislead parents to achieve the purpose of selling courses. In terms of evaluation methods, most early childhood education institutions use observation and test methods more. The standard of the test tools used by teachers and the accuracy of the evaluation conclusion are to be further verified in scientific way.

\section{SUGGESTIONS FOR OPTIMIZING THE CURRICULUM OF EARLY CHILDHOOD EDUCATION}

\section{A. The Government Should Formulate Relevant Laws and Standards to Promote the Normalized Development of Early Childhood Education Institutions}

China needs to promulgate relevant laws and regulations, establish and improve the supervision system for early childhood education institutions, clarify the management responsibilities of various government departments, especially the education department's supervision responsibility for early childhood education institutions, and strengthen supervision on early childhood education institution's education process. China should formulate detailed standard of early childhood education course for children aged 0-3 and standard for teachers in early childhood education institution, and strive to protect the scientific nature, suitability and development of early childhood education institution courses, as well as teachers' professional quality. China should strictly control the market access, implement strict registration and approval systems for early childhood education institutions, and cancel any early childhood education institution with unreasonable curriculum settings and lack of professional teachers. [5]

\section{B. Constructing a Curriculum System with Strong Applicability and Adaptive to the Local Conditions}

"Stones of other mountains can be used to attack jade." Foreign curriculum systems such as Montessori courses, Reggio courses, Orff music courses, and sensory integration courses do have their advanced, excellent, and desirable natures, but it is not wise to simply copy it without any adjustment and improvement. China can learn from, absorb, and integrate advanced foreign curriculum concepts and curriculum systems, but must take into account the actual development situation and needs of infants and children aged $0-3$, and fully consider the social and cultural background, economic development status, and local customs of the country and region. On this basis, relying on scientific education theories and rich educational practices and contemplate ideas, China should strive to build a curriculum system that is supported by scientific theories and rich educational practices and reflects Chinese characteristics and regional characteristics, and abandon the curriculum system 
simply copied, to enhance the applicability of the curriculum system.

\section{Accurate Positioning and Strengthening the Pertinence of the Course Goals}

$80 \%$ of infants aged 0-3 live in their family. Parents or grandparents are the first subject to implement early childhood education on them. Daily life is the main way to implement the education. The purpose of setting up early childhood education institutions should be to "promote infants' development of physical and mental health by improving the subject's teaching and caring level. Early childhood education institutions should become a counseling, demonstration and guidance institution for every family to implement early childhood education. The curriculum of early childhood education institutions should be a guiding course for parenting activities and affect the micro-system of infants' growth by affecting the parents to improving the parenting atmosphere at home. [6] The parent-child course once or several times a week should be based on the development characteristics of infants and young children, focus on providing guidance to parents' parenting activities, imparting scientific parenting knowledge to parents, optimizing parents' educational concepts, and teaching parents how to observe infants' behaviors in daily life through specific activities and how to apply targeted parenting knowledge, method and skills that can meet infants' needs and give positive response to infants so that the parent-children interaction in daily life becomes a scientific parenting process. Teachers also need to observe carefully to know about the development level, existing knowledge and experience, hobbies and so on of each infant, pay attention to the differences of each child, and apply suitable teaching plan.

\section{Keeping Close to Reality and Enhancing the Flavor of Life of the Course Content}

The curriculum of early childhood education institutions should not only attach importance to the novelty and interestingness of educational activities, but also pay attention to the life experience of infants and parents. It should provide suitable content based on the life experience of infants and parents to enhance infants and parents' true feelings. In the traditional game-oriented early childhood education courses, the contents of feeding, bathing, falling asleep and other life links can be added to reflect the concept of integrating parenting and education. Through those links, the curriculum content is full of the flavor of life; teacher can improve infants' positivity and true feeling in participating in early childhood education course based on the familiarity of infants and parents with the curriculum content, to further guide parents to master correct parenting skills and education-parenting integrated method. At the same time, teacher should teach parents how to timely take the various opportunities of infants and toddlers in the institution to provide infiltration education, and to integrate the fragmented and scattered life experiences acquired by infants and children in specific courses.

\section{E. Renewing the Concept and Integrating It into the Creativeness of Curriculum Implementation}

The characteristics of curriculum creation are being practical, generative, constructive, reflective, dynamic, and open. Curriculum creation organically integrates teacher's development, children's development, and curriculum development. [7] During the course implementation, teacher should accurately grasp the physical and mental development laws and learning characteristics of infants aged 0-3, clarify the key points of infant and child parenting at this age, correctly interpret the reactions and behaviors of parents and infants, respond to the specific implementation situation, make timely adjustments to the adverse reactions of infants and young children during the course implementation, innovate the course implementation process and links, create curriculum resources and enrich the curriculum content, so as to better meet the needs of infants and parents and enhance the flexibility and vividness of the course implementation.

\section{F. Formulating a Scientific Evaluation System Oriented to Development}

Early childhood education institution should be oriented to promoting the development of infants and young children, establish a standard and scientific curriculum evaluation system that can both evaluate the curriculum setting and plan, and the course implementation process and effect. Teachers in the institutions, parents and infants should be involved in the subject of the evaluation; teacher should choose scientific evaluation tools and standards, observe carefully, analyze the works of infants and young children and communicate with parents, to know about the development status of each infant and evaluate their development level; teacher should also guide parents learn to make scientific evaluation on their children's development status by daily observation and take corresponding educational measures. At the same time, it is also needed to add the evaluation on the designed curriculum content, educational activities and plans, the evaluation on the degree of parents' benefit, in order to better improve the curriculum evaluation structure and establish a comprehensive and systematic curriculum evaluation system.

\section{CONCLUSION}

Early childhood education for infants aged 0-3 plays an important role in the development of their lives. There is an over-emphasis on foreign advanced educational theories in China's early childhood education institutions, while neglecting the trend of localization. Teachers and management personnel in many early childhood education institutions lack theoretical foundations, and it is more common to focus on education other than parenting. The curriculum goals of early childhood education institutions are not clear; they are too restricted to a certain form and lack substantial content; and the curriculum evaluation system is not perfect enough. Based on the above research findings, it is recommended that relevant authorities formulate relevant policies as early as possible to regulate some irregular situations. At the same time, localized early childhood education courses should be developed in 
accordance with local conditions and in combination with advanced foreign theories. There should be more systematic and in-depth research on the goals, positioning, and evaluation of early childhood education courses; and a scientific early childhood education curriculum system and evaluation system should be formulated. This is conducive to the improvement of the educational quality and effect of early childhood education institutions in China, can greatly promote the development of early childhood education in China, and further providing a more scientific, safe and healthy space for the healthy development of children in China in the early childhood.

\section{REFERENCES}

[1] Liu Juan. Research on the curriculum setting of early childhood education institutions in Hohhot [D]. Hohhot: Inner Mongolia Normal University, 2014. (in Chinese)

[2] Shen Minting. Research on the Problems in the Parent-child Curriculum for Children Aged 0-3 - Taking Parent-child Garden of Foreign Chain Brands as an Example [J]. Family Education, 2013 (4): 179. (in Chinese)

[3] Wen Yi, Yang Chunhua. Several problems to be sorted out in the parent-child curriculum for children aged 0-3 [J]. Early childhood education, 2010 (2). (in Chinese)

[4] Meng Ping. A Comparative Study of Early childhood education Courses for Children Aged 0-3: Taking Two early childhood education institutions in Jinan as Examples [D]. Jinan: Shandong Normal University, 2014. (in Chinese)

[5] Zhang Han. The main problems existing in Chinese early childhood education institutions and the countermeasures [J]. Jiangsu Infant Education, 2014 (1): 47. (in Chinese)

[6] Wu Lingling. Entering the Parent-child Garden [M]. Shanghai: China Welfare Press, 2008: 56. (in Chinese)

[7] Xiang Haiying. Curriculum enactment: an inevitable choice for the reform of preschool education curriculum [J]. Studies in Preschool Education, 2007 (6): 36. (in Chinese) 